\title{
The role of wastewater treatment plants in surface water contamination by plastic pollutants
}

\author{
Bozena Mrowiec ${ }^{1, *}$ \\ ${ }^{1}$ University of Bielsko-Biala, Faculty of Materials, Civil and Environmental Engineering, Institute of \\ Environmental Protection and Engineering, Willowa 2, 43-309 Bielsko-Biala, Poland
}

\begin{abstract}
The aim of this paper was to review the literature data regarding the physico-chemical characteristic of plastic pollutants discharged with municipal sewage, the practical possibility of removing microplastic particles from wastewater during different treatment steps in WWTPs and the problem of surface water contamination within them. Microplastics (the size range of $1 \mathrm{~nm}$ to $<5 \mathrm{~mm}$ ), have been recognized as an emerging threat, as well as an ecotoxicological and ecological risk for water ecosystems. Municipal wastewater treatment plants (WWTPs) are mentioned as the main point sources of microplastics in an aquatic environment. Microplastic particles can be effectively removed in the primary treatment zones via solids skimming and sludge settling processes. Different tertiary treatment processes such as: gravity sand filtration, discfilter, air flotation and membrane filtration provide substantial additional removal of microplastics, and the efficiency of wastewater treatment process can be at a removal level of $99.9 \%$. Nevertheless, given the large volumes of effluent constantly discharged to receivers, even tertiary level WWTPs may constitute a considerable source of microplastics in the surface water.
\end{abstract}

\section{Introduction}

In 2016, global plastic production was estimated at 335 million tonnes, in Europe it was at the level of 60 million tonnes. The six larger European countries and the Benelux have covered almost $80 \%$ of the European demand in 2016 (49.9 million tonnes). The main market sectors of converter demand are: packaging 39.9\%, building and construction $19.7 \%$, automotive $10 \%$, electrical and electronic $6.2 \%$, household, leisure and sports $4.2 \%$, agriculture 3.3\%, others (includes appliances, mechanical engineering, furniture, medical etc.) $16.7 \%$. In 2016, 27.1 million tonnes of plastic post-consumer waste was collected. And for the first time, more plastic waste was recycled than landfilled [1]. Yet, about 1\% (0.27 million tonnes) of total plastic demand ends up in dumpsites [2].

Plastic pollutants have been identified in the oceans, seas and more recently in freshwater systems. Moreover, the contaminants are ingested by various aquatic organisms

\footnotetext{
* Corresponding author: bmrowiec@ath.bielsko.p1
} 
and trophic level transfer of microplastics has also been shown to occur [3-4]. In addition to marine microplastic input into our diet by consuming fish and seafood that may by contaminated by leaking pollutants and additives in microplastic, the direct exposure of microplastics to humans via other sources, especially such as drinkable water, needs to be considered. Currently, there is almost no published science data on the microplastics content of drinking or mineral water available. But, information about plastic fibres found in tap water around the world appears.

It is estimated that $70-80 \%$ of plastic contaminants originate from land-based sources and they are transported by rivers to the seas and oceans [5-10]. Plastic pollution may enter into surface waters through multiple pathways, including stormwater runoff, wind advection and atmospheric fallout, and treated wastewater discharges. Municipal wastewater treatment plants (WWTPs) are mentioned as the main point sources of microplastics in an aquatic environment [8, 10-14]. Microbeads used in cosmetics and household products are transported in raw effluent to WWTP where because of their small size they may bypass the treatment process $[8,10]$. Similarly, synthetic clothing, such as polyester and nylon, is also a concern as these fabrics can shed thousands of fibres into wastewater under washing [10-11]. A number of factors may affected the contribution of wastewater as a source of microplastics and also the dominant type of wastewater-based microplastics in a specific area including (i) population density, (ii) the number and type of industries involved in producing plastics, (iii) the level of wastewater treatment, (iv) public awareness with respect to microplastics and their subsequent effects and (v) waste management processes [15]. During the last decades the right wastewater treatment technology has continuously been required to increase the quality of final effluents. However, the technologies to improve the quality of final effluent are not specifically designed to remove microplastics. Therefore, at present, a high efficiency of wastewater treatment processes is important, because they are likely hubs for microplastics between the consumer and the environment and WWTPs are a key place where the microplastic load may be able to be reduced and it will not be discharged into the water environment.

The aim of this paper was to review the literature data regarding the physico-chemical characteristic of plastic pollutants discharged with municipal sewage, the practical possibility of removing microplastic particles from wastewater during different treatment steps in WWTPs and the problem of surface water contamination within them.

\section{Plastic pollutants}

Seven main classes of plastics are produced: polyethylene (PE), polypropylene (PP), polyvinyl chloride (PVC), polystyrene (PS), Polyamide (PA), polyurethane (PUR) and polyethylene-terephthalate (PET) $[5,7,16-17]$. The most commonly used plastics are PE, PP, PVC, PS and PET, which represent about $90 \%$ of the global production [2, 15]. Consequently, the majority of released plastics in the environment are composed of these polymers. Plastic pollutants are present in the water environment in a wide variety of sizes, ranging from micrometres to metres. They are commonly categorized by size: microplastics (items less than $5 \mathrm{~mm}$ in length), mesoplastics $(5 \mathrm{~mm}-2 \mathrm{~cm})$ or macroplastics $(>2 \mathrm{~cm})[2$, 18]. The smallest particles are defined as nanoplastics, as the contaminants are of the size of nanoparticles $(<100 \mathrm{~nm})$. Plastic pollutants, depending on the type of material and particle size, can sink on to the bottom sediments or float on the water surface. Apart from the main monomer, plastics contain a variety of organic plastic additives added during their manufacture (i.e., initiators, catalysts, solvents, antimicrobial agents, surfactants, plasticizers, flame retardants, lubricants, dispersant, antistatic agents, nanoparticles, fillers, fragrances and pigments) [8, 19-20]. Because the main issue of this review are plastic pollutants in wastewater, further considerations will be limited to microplastics. 
Microplastics (MPs) are classified as primary and secondary. Primary MPs are polymers intentionally manufactured at a microscopic scale (the size range of $1 \mathrm{~nm}$ to $<5$ $\mathrm{mm}$ ) through the process of extrusion or grinding. Primary microplastics as microbeads are still used in personal care products with exfoliating purposes, such as facial cleansers, cosmetics and medical applications - drug vectors. For these applications the microbeads are mainly composed of PE and PP. After being used, the microbeds from cosmetics and personal care products are washed down the drains and the microplastics are carried via wastewater to municipal WWTPs. Primary microplastics also include industrial abrasives or scrubbers used to blast clean surfaces or plastic powders used in modelling and drilling fluids for oil and gas exploration. Plastic pellets as raw material are used for plastic fabrication for many industrial applications [17, 21-27].

Secondary MPs are formed during the degradation of macroplastics due to the mechanical, photolytic and/or chemical degradation of bigger plastic fragments in water environment and often result in fragmented pieces or fibres [19, 23-26]. The most important route of secondary microplastics into the environment is their loss from the inappropriate management of landfill sites and during waste collection. Moreover, the sources of secondary microplastics are: littering and dumping of plastic waste, losses of plastic material during natural disasters, abrasion-release of fibres from synthetic textiles and hygiene products, abrasion from car tyres, plastic items in organic waste and another [27].

\section{Microplastic pollutants in WWTPs}

\subsection{Microplastics in wastewater}

Wastewater treatment plants receive wastewater from households, institutions, commercial establishments, and industries and sometimes also from rainwater runoff from urban areas. Conventional wastewater treatment technology includes two steps: primary and secondary, and sometimes tertiary treatments.

Microplastics, for example, from cosmetics, toothpaste, synthetic fibres from textiles and other plastic waste, end up at the municipal WWTPs [8, 27]. A single polyester fibre shirt releases 1900 fibres in a single washing [11]. It was assessed that the input of MPs raised by personal care products from sewage amounted to approximately $7.5 \mathrm{~g} / \mathrm{person} \cdot y e a r$ [2]. Primary and secondary treatment processes can remove MPs from the sewage up to $99 \%$ [28], but the large volumes of effluent that are discharged to receivers can result in a significant amount of plastic pollutants [10].

Some recent studies demonstrated wastewater treatment plants (WWTPs) as the main sources of microplastics that pollute the aquatic environment [8, 12, 14, 31-32]. On the other hand, the correlation between WWTPs and microplastic pollution found in rivers could not be definitively corroborated [29-31].

The content of microplastics in WWTP influent vary in the range of $10^{4}$ to $10^{5}$ microplastics $/ \mathrm{m}^{3}$ and their incomplete removal (70-100\%) during the treatment process can result in pollution in the receiving water [14]. Recently, there have been a number of pilot studies assessing the removal efficiency and load of MPs in WWTPs in different areas of world. The results are summarized in Table 1.

Mintening et al. [12] have detected MPs $>500 \mu \mathrm{m}$ in 10 effluents from 12 German WWTPs in Lower Saxony. Eight synthetic polymers were identified, but dominant were PE (59\%) and PP (16\%). Other polymers occurred sporadically. The MPs $>500 \mu \mathrm{m}$ were not present in the effluent after post-filtration. All the analysed effluent contained MPs in the size $<500 \mu \mathrm{m}$. The microplastic particles comprised 14 polymers and similarly the dominant was PE (40\%). The authors stated discharging of microplastic particles $<500 \mu \mathrm{m}$ 
with quantities ranging from $8 \cdot 10^{1} / \mathrm{m}^{3}$ to $9 \cdot 10^{3} / \mathrm{m}^{3}$ and synthetic fibres from $1 \cdot 10^{2} / \mathrm{m}^{3}$ to $5 \cdot 10^{3} / \mathrm{m}^{3}$. The application of post-filtration in the WWTP in Oldenburg decreased the amount of MPs from $2 \cdot 10^{2} / \mathrm{m}^{3}$ to $1 \cdot 10^{1} / \mathrm{m}^{3}$ and reduced the load of synthetic fibres from $9 \cdot 10^{2} / \mathrm{m}^{3}$ to $2 \cdot 10^{1} / \mathrm{m}^{3}$. The estimated annual discharge for the MPs and synthetic fibres from the investigated WWTPs ranged respectively from $1 \cdot 10^{7} /$ year to $5 \cdot 10^{9} /$ year and 3 . $10^{7} /$ year to $3 \cdot 10^{9} /$ year. Good efficiency of wastewater treatment in the range of plastic pollutants removal was stated by Talvitie et al. [31]. The treatment process, which included biological filtration improved the removal of MPs. The microplastic load in the effluent was found to be an average of $8.6 \cdot 10^{3}$ particles and $4.9 \cdot 10^{3}$ fibres per $\mathrm{m}^{3}$ of wastewater. Yet, despite the high efficiency of wastewater treatment, the average content of fibres was 25 times higher and the content of particles was 3 times higher in the effluent compared to the receiving water body. The investigation of the MPs in wastewater at the subsequent stages of the treatment process showed large differences in their content. In raw sewage the average content of MPs ranged from $380 \cdot 10^{3}$ particles $/ \mathrm{m}^{3}$ to $686.7 \cdot 10^{3}$ particles $/ \mathrm{m}^{3}$, after pre-treatment from $9.9 \cdot 10^{3}$ particles $/ \mathrm{m}^{3}$ to $14.2 \cdot 10^{3}$ particles $/ \mathrm{m}^{3}$, after activated sludge process from $1 \cdot 10^{3}$ particles $/ \mathrm{m}^{3}$ to $2 \cdot 10^{3}$ particles $/ \mathrm{m}^{3}$ and in the effluent $0.7 \cdot 10^{3}$ particles $/ \mathrm{m}^{3}$ to $3.5 \cdot 10^{3}$ particles $/ \mathrm{m}^{3}$ [14]. But the results did not confuse the results obtained earlier by Talvitie et al. [31], because the tertiary biological active filter did not decrease the content of MPs in the effluent. And even, on the example of the above presented results, the discharged effluent contained more microplastic particles than the wastewater after the second step of treatment. The next experiments of Talvitie et al. [28] in four different municipal WWTPs utilizing an advanced final-stage (tertiary) treatment process have resulted in high efficiency of the removal of MPs. The authors stated discfilter application with a pore size of $10 \mu \mathrm{m}$ removed MPs on the average level $98,5 \%\left(0.03 \cdot 10^{3}\right.$ particles $/ \mathrm{m}^{3}$ in the effluent), for rapid sand filter it was respectively $97.1 \%\left(0.02 \cdot 10^{3}\right.$ particles $\left./ \mathrm{m}^{3}\right)$, for dissolved air flotation $95 \%\left(0.1 \cdot 10^{3}\right.$ particles $\left./ \mathrm{m}^{3}\right)$. In the case of the above final-stage treatments, secondary effluents for tertiary treatment was used. However, the best results were determined for membrane bioreactor as a final treatment for primary effluent. The efficiency of the removal of MPs was stated at the average level of $99.9 \%$ and outflow contained $0.005 \cdot 10^{3}$ particles $/ \mathrm{m}^{3}$. A very high efficiency of microplastics removal $(99.9 \%)$ in the wastewater treatment process had been confirmed by Carr et al. [29]. Similarly, the authors stated, that microplastic particles are removed in the primary treatment zones via solids skimming and sludge settling processes, and the effluents discharge from secondary and tertiary wastewater treatment facilities can contain only minimal microplastic loads discharged. An average of one microplastic particle in every $1.14 \mathrm{~m}^{3}$ of discharged effluent was counted. Michielssen et al. [32] have presented the efficiency of secondary wastewater treatment in the US at the average level of $95.5 \%$ of the removal of MPs, and discharging $5.9 \cdot 10^{3}$ particles $/ \mathrm{m}^{3}$ in the final effluent. The application of gravity sand filtration as the tertiary wastewater treatment increased the retention of MPs to $97.2 \%$. In this case the effluent contained $2.6 \cdot 10^{3}$ particles $/ \mathrm{m}^{3}$. The best efficiency for the removal of MPs was obtained for the membrane filtration as the tertiary wastewater treatment. The average efficiency was at the level of $99.4 \%$ and the final outflow counted only $0.5 \cdot 10^{3}$ particles $/ \mathrm{m}^{3}$. In the effluents from WWTPs with a tertiary treatment process, thin fibres represented a large percentage of MPs ranging from 79 to $83 \%$. Also, low contents of microplastic in the final effluent of WWTPs in the range $0.21 \cdot 10^{3}$ particles $/ \mathrm{m}^{3}$ to $0.28 \cdot 10^{3}$ particles $/ \mathrm{m}^{3}$ were stated by Ziajahromi et al. [15]. The authors have tested reverse osmosis as an advanced tertiary treatment process. For this process, the obtained results for the removal of MPs were the best; but even after the advanced wastewater treatment process the MPs were not completely removed. The researchers suggest, similar to Mintening et al. [12] and Michielssen et al. [32], that synthetic fibres from textiles are a bigger issue than microplastic beads from personal care products, and that it requires 
urgent attention. Kalčikovă et al. [33] have performed experiments in a lab-scale sequencing batch biological WWTP and they obtained a relatively low efficiency of microbeads removal at an average level of $52 \%$. The authors stated, that smaller particles (up to $60-70 \mu \mathrm{m}$ ) were captured within activated sludge, while larger particles were detected in the effluent. The investigations showed that about 112,500,000 particles may daily be released into the receiving river, resulting in a microbeads content of 21 particles $/ \mathrm{m}^{3}$.

As described above, many authors suggested that WWTPs can be considered as playing an important role for receiver pollution. Yet, there are researchers who do not confirm there is a direct link between plastic contaminants in rivers and WWTPs [29, 34]. It should be noted, that most rivers with a high rate of plastic waste are located close to large urban centres. The significance of the wastewater pathway for microplastic contamination relative to other pathways, like stormwater run-off, wind-blown debris, and in situ degradation of larger plastic items, is unknown and requires additional study [13].

Table 1. The average content of MPs in wastewater after treatment and removal efficiency.

\begin{tabular}{|c|c|c|c|c|c|}
\hline $\begin{array}{c}\text { Study } \\
\text { country }\end{array}$ & Treatment & $\begin{array}{c}\text { Effluent } \\
\text { type }\end{array}$ & $\begin{array}{c}\text { MPs content } \\
\text { (MPs/L) }\end{array}$ & $\begin{array}{c}\text { Removal } \\
\text { (\%) }\end{array}$ & Reference \\
\hline Germany & $\begin{array}{c}\text { Post } \\
\text { filtration }\end{array}$ & Tertiary & $\begin{array}{c}0.01 \text { particles } \\
0.02 \text { fibres }\end{array}$ & 97 & {$[12]$} \\
\hline Finland & $\begin{array}{c}\text { Biological } \\
\text { filtration }\end{array}$ & Tertiary & $\begin{array}{c}8.6 \text { particles } \\
4.9 \text { fibres }\end{array}$ & $\begin{array}{c}98.0 \\
97.0\end{array}$ & {$[31]$} \\
\hline Finland & $\begin{array}{c}\text { Discfilter } \\
\text { pore } 10 \mu \mathrm{m}\end{array}$ & Tertiary & 0.03 & 98.5 & {$[28]$} \\
\hline Finland & $\begin{array}{c}\text { Rapid sand } \\
\text { filter }\end{array}$ & Tertiary & 0.02 & 97.1 & {$[28]$} \\
\hline Finland & $\begin{array}{c}\text { Dissolved } \\
\text { air flotation }\end{array}$ & Tertiary & 0.1 & 95.0 & {$[28]$} \\
\hline Finland & $\begin{array}{c}\text { Membrane } \\
\text { bioreactor }\end{array}$ & Tertiary & 0.005 & 99.9 & {$[28]$} \\
\hline United States & $\begin{array}{c}\text { Gravity } \\
\text { filter }\end{array}$ & Tertiary & 0.0008 & 99.9 & {$[29]$} \\
\hline United States & $\begin{array}{c}\text { Activated } \\
\text { sludge }\end{array}$ & Secondary & 5.9 & 95.9 & {$[32]$} \\
\hline United States & $\begin{array}{c}\text { Gravity } \\
\text { filter }\end{array}$ & Tertiary & 2.6 & 97.2 & {$[32]$} \\
\hline United States & $\begin{array}{c}\text { Membrane } \\
\text { filtration }\end{array}$ & Tertiary & 0.5 & 99.4 & {$[32]$} \\
\hline United States & $\begin{array}{c}\text { Average values for 17 } \\
\text { WwTPs with secondary and } \\
\text { tertiary treatment }\end{array}$ & 0.017 particles \\
0.03 fibres & Nd & {$[13]$} \\
\hline Australia & $\begin{array}{c}\text { Reverse } \\
\text { osmosis }\end{array}$ & Tertiary & $0.21-0.28$ & Nd & {$[15]$} \\
\hline Scotland & $\begin{array}{c}\text { Biological } \\
\text { and } \\
\text { chemical }\end{array}$ & Secondary & 0.25 & 98.4 & {$[10]$} \\
\hline Slovenia & $\begin{array}{c}\text { Activated } \\
\text { sludge }\end{array}$ & Secondary & Nd & 52 & {$[33]$} \\
\hline
\end{tabular}

"Nd" - not detected

\subsection{Microplastics in sewage sludge}

In WWTPs, primary skimming and settling processes have the greatest effect leading to high amounts of PMs in sewage sludge. Murphy et al. [10] stated that solid fraction (grit, 
grease, sludge) have accumulated high amounts of MPs. Especially, polyethylene microbeads were found in grease samples. The microbeads are positively buoyant in water and likely to sit on the surface of wastewater where they can be easily skimmed off the surface layer during grease removal. In influent textile synthetic fibres probably attach easily to grit and to other larger organic waste material and settle down in sludge efficiently during primary sedimentation. It was estimated that $80 \%$ of the microplastics from raw sewage is retained in the dried sludge [14]. Mintenig et al. [12] stated a contamination of MPs $<500 \mu \mathrm{m}$ in all of the 6 German WWTPs analysed, but none of the sludge samples contained MPs $>500 \mu \mathrm{m}$. The content of PMs were in the range from $1 \cdot 10^{3}$ particles $/ \mathrm{kg}$ dry weight (d.w.) to $2.4 \cdot 10^{4} / \mathrm{kg}$ d.w. It was estimated that for the annual production of sewage sludge the MP content in its was from $1.24 \cdot 10^{9} /$ year to $5.67 \cdot 10^{9} /$ year. Talvitie et al. [14] determined the average contents of MPs in mixture of excess and raw sludge, dry sludge and reject water. The values were respectively 63611.1 particles/L in excess and raw sludge mixture, $186.7 \cdot 10^{3}$ particles $/ \mathrm{kg}$ d.w. and 12866.7 particles/L in reject water. The authors stated, that when MPs not removed from WWTP with effluent or dried sludge, microplastic particles are recycled inside the WWTP with the activated sludge and reject water. Approximately $20 \%$ of the MPs removed from the process are recycled back into the reject water, whereas $80 \%$ of the MPs are contained in the dried sludge [14].

\section{Microplastics in water environment}

Both primary and secondary MPs are found in environmental samples. All types of plastics have been recognized as an emerging threat, as well as an ecotoxicological and ecological risk for water ecosystems [7]. Plastics have a hydrophobic nature, therefore, they can adsorb other dangerous organic and inorganic contaminants such as: endocrine-disrupting compounds, pharmaceuticals, polychlorinated biphenyls (PCBs), polycyclic aromatic hydrocarbons (PAHs), polybrominated diphenyl ethers (PBDEs), and heavy metals from the surrounding water and so on $[4,17,22,26,29,35-37]$. The degradation processes of synthetic plastic pollutants are slow, therefore, the particles persist for a very long time in an aquatic environment and become available to water organisms [20]. In an aquatic environment, the following degradation processes can occur: (i) biodegradation (the action of living organisms - microbes), (ii) photodegradation (the action of light - sunlight), (iii) thermo-oxidative degradation (slow oxidative breakdown at moderate temperatures) and (iv) hydrolysis (reaction with water) [38-39]. The shape of particles determine the interaction of plastic pollutants with the biological system. A more irregular shape may attach more readily to internal and external surfaces and exert a greater toxic effect [19]. The bioavailability of plastic particles increases with decreasing size, making them easily available to smaller trophic organisms [36, 40-41]. The reduction of plastic particles to a micro- and nano-scale can lead to an increase in their sorption properties and in the transport of harmful compounds from plastics into water organisms [26, 35]. Microplastics can be hazardous to aquatic organisms through different pathways. First, the ingestion of MPs can cause physical blockage, internal abrasions, and internal and external wounds, and hence the organisms can be harmed by expending energy for digestion, can suffer from starvation and debilitation, and can result in death. Second, the organisms can be exposed to the leakage of toxic additives. The additives may not only be toxic but also carcinogenic or endocrine active, which can impact the reproductive functions of the species [27]. Moreover, microplastics floating in water have the tendency of providing raft substrates for various epifauna and microbes (i.e., bacteria, algae, diatoms, barnacles, hydroids, tunicates) and transporting them to areas where they had not existed before [17]. 


\section{Summary}

Conventional wastewater treatment technology mainly includes two steps: primary and secondary, and nowadays it can be insufficient for microplastic pollutants removal. WWTPs utilizing advanced final-stage (tertiary) treatment process have resulted in the high efficiency of the removal of MPs, even to $99.9 \%$. But, despite the high efficiency of wastewater treatment, the large volumes of effluent constantly discharged into the receiver may constitute a considerable source of microplastic particles introduced into surface waters. Studies on microplastics exposure and their removal in WWTPs found different quantities. The result can widely differ in terms of validity and resilience, because different techniques of sampling, preparation an analytical equipment are used in the investigations. Moreover, current studies in microplastic pollution issue do not take into account stormwater runoff, where untreated effluent is released directly into rivers. Untreated wastewater may potentially and heavily increase the amount of MPs entering the receiving environment. Therefore, the issue of stormwater overflow should be investigated and it should also be taken into account in relation to water environment contamination by microplastic pollutants. The next important issue is the problem of sewage sludge used in agriculture and green construction. The very high content of MPs in dry sludge allows a large load of MPs to possibly be introduced into the environment with the sludge. It should be emphasised that the presented data in many cases focused on a single sampling campaign. Therefore for the better explanation of WWTPs as a pathway for MPs to the aquatic environment, long-term monitoring studies are necessary.

\section{References}

1. Plastics- the Facts (2017) (online, available from https://www.plasticseurope.org/application/files/5715/1717/4180/Plastics_the_facts_20 17_FINAL_for_website_one_page.pdf)

2. D. Venghaus, M. Barjenbruch, Technical Transactions 1, 137-146 (2017)

3. R. Lohmann, Integr. Environ. Assess. Manage. 13, 3, 460-465 (2017)

4. D. Eerkes-Medrano, R.C. Thompson, D.C. Aldridge, Water Res. 75, 63-82 (2015)

5. A.L. Andrady, Mar. Pollut. Bull. 62, 1596-1605 (2011)

6. J.R. Jambeck, R. Geyer, C. Wilcox, T.R. Siegler, M. Perryman, A. Andrady, R. Narayan, K. Lavender Law, Science 347, 6223, 768-771 (2015)

7. C.G. Avio, S. Gorbi, F. Regoli, Mar. Environ. Res. 128, 2-11 (2016)

8. J.P. da Costa, P.S. Santos, A.C. Duarte, T. Rocha-Santos, Sci. Total Environ. 566-567, 15-26 (2016)

9. C.A. Peters, S.P. Barton, Environ. Pollut. 210, 380-387 (2016)

10. F. Murphy, C. Ewins, F. Carbonnier, B. Quinn, Environ. Sci. Technol. 50, 5800-5808 (2016)

11. A. Stolte, S. Forster, G. Gerdts, H. Schubert, Mar. Poll. Bull. 99, 216-229 (2015)

12. S. M. Mintening, I. Int-Veen, M.G. Löder, S. Primpke, G. Gerdts, Water Res. 108, 365-372 (2017)

13. S. Mason, D. Garneau, R. Sutton, Y. Chu, K. Ehmann, Environ. Pollut. 218, 1045-1054 (2016)

14. J. Talvitie, A. Mikola, O. Setälä, M. Heinonen, A. Koistinem, Water Res. 109, 164-172 (2017) 
15. S. Ziajahromi, P.A. Neale, F.D. Leusch, Water Sci. Technol. 74, 10, 2253-2269 (2016)

16. B. J. Laglbauer, R.M. Franco-Santos, M.A. Andreu-Cazenave, L. Brunelli, M. Papadatou, A. Palatinus, M. Grego, T. Deorez, Mar. Pollut. Bull. 89, 356-366 (2014)

17. O.O. Solomon, T. Palanisami, J. Pollut. Eff. Cont. 4, 2 (2016) http://dx.doi.org/10.4172/2375-4397.1000161

18. J. Lee, S. Hong, Y.K. Song, S.H. Hong, Y.C. Jang, N.W. Heo, G.M. Han, M.J. Lee, D. Kang, Mar. Pollut. Biull. 77, 1, 349-354 (2013)

19. S. Lambert, S. Christian, M. Wagner, Integr. Environ. Assess. Manage. 13, 3, 470-475 (2017)

20. B. J. Laglbauer, R.M. Franco-Santos, M.A. Andreu-Cazenave, L. Brunelli, M. Papadatou, A. Palatinus, M. Grego, T. Deprez, Mar. Pollut. Bull. 89, 356-366 (2014)

21. M. Cole, P. Lindeque, C. Halsband, T.S. Galloway, Mar. Pollut. Bull. 62, 2588-2597 (2011)

22. V. Hidalgo-Ruz, L. Gutow, R.C. Thomoson, M. Thiel, Environ. Sci. Technol. 46, 3060-3075 (2012)

23. L.Van Cauwenberghe, L. Devriese, F.Galgani, J. Robbens, C.R. Janssen, Mar. Environ. Res. 111, 5-17 (2015)

24. C. Alomar, F. Estarellas, S. Deudero, Mar. Environ. Res. 115, 1-10 (2016)

25. C.A. Peters, S.P. Bratton, Environ. Pollut. 210, 380-387 (2016)

26. B. Graca, K. Szewc, D. Zakrzewska, A. Dolega, M. Szczerbowska-Boruchowska, Environ. Sci. Pollut. Res. 24, 7650-7661 (2017)

27. H. Westphalen, A. Abdelrasoul, Intech, Chapter 5, 71-83 (http://dx.doi.org/10.5772/intechopen.71494)

28. J. Talvitie, A. Mikola, A. Koistinen, O. Setälä, Water Res. 123, 401-407 (2017)

29. S.A. Carr, J. Liu, A.G. Tesoro, Water Res. 91, 174-182 (2016)

30. S. Estahbanati, N.L. Fahrenfeld, Chemosphere 162, 277-284 (2016)

31. J. Talvitie, M. Heinonen, J.P. Pääkkönen, E. Vahtera, A. Mikola, O. Setälä, R. Vahala, Environ. Sci. Technol. 72, 9 1495-1504 (2015)

32. M.R. Michielssen, E.R. Michielssen, J.Ni, M.B. Duhaime, Environ. Sci. :Water Res. Technol. 2, 1064-1073 (2016)

33. G. Kalčikovă, B. Alič, T. Skalar, M. Bundschuh, A. Žgajnar Gotvajn, Chemosphere 188, 25-31 (2017)

34. S. Estahbanati, N.L. Fahrenfeld, Chemosphere 162, 277-284 (2016)

35. Y. Ma, A. Huang, S.Cao, F. Sun, L. Wang, H. Guo, Environ. Pollut. 219, 166-173 (2016)

36. C. Pinheiro, U. Oliveira, M. Vieira, J. Aquac. Mar. Biol. 5, 6, (2017) 00138. DOI:10.15406/jamb.2017.05.00138. 2017

37. S.L. Wright, F.J. Kelly, Environ. Sci. Technol. 51, 6634-6647 (2017)

38. A.L. Andrady, Mar. Pollut. Bull. 62, 1596-1605 (2011)

39. J.A. Ivar do Sul, M.F. Costa, Environ. Pollut. 185, 352-364 (2014)

40. O. Setala, V. Fleming-Lehtinen, M. Lehtiniemi, Environ. Pollut. 185, 77-83 (2014)

41. Y. Chae, Y.J. An, Mar. Pollut. Bull. 124, 624-632 (2017) 